\title{
Flood risk assessment and scenarios for a flood insurance program in central Vietnam
}

Thoa Thi Thu Hoang (1), Magali E. Zuanon (2), Tu Vu (3), and Roberto Ranzi (4)

(1) Thuyloi University, Faculty of Economics and Management, Hanoi, Vietnam, (2) Universita' degli Studi di Brescia, Dipartimento di Economia e Management, Brescia, Italy, (3) Thuyloi University, Faculty of Hydrology and Water Resources, Hanoi, Vietnam, (4) Universita' degli Studi di Brescia,Dipartimento di Ingegneria Civile, Architettura, Territorio, Ambiente e di Matematica, Brescia, Italy (roberto.ranzi@unibs.it)

Severe floods occur in several coastal area of Vietnam and causes both properties and causalities. It is important to guide local households in selecting risk management strategies according to their capacity to reduce significant damage (Molinari et al). Insurance was recently recognized as one of the possible non structural measures to mitigate losses and damages from natural disasters (UNISDR, 2015). Despite the huge effect on citizens' life from flood risk and believable higher damages caused by flood in the future due to climate change, it is surprising that there is no flood insurance program in Vietnam. This paper investigates the vulnerability of households to flood and suggests a conceptual framework to implement possible scenarios of flood insurance programs for Central Vietnam. We implement 2D simulations of the physical hazard in term of flooding, velocity, depth and duration, and then combined the flood hazard maps, exposure and vulnerability maps to obtain risk maps. We calculate major flood damages, regarding housing damages and paddy rice damages, for five different return periods $(10,20,50,100,200$ years). Based on 386, out of 400 responses to 35 questions in a questionnaire directly related to flood risk and preparedness, the vulnerability curve for direct tangible costs to building structure, building contents, and paddy rice were assessed. We also find that, in the long term, with a proper flood insurance premium, three actors (Vietnam Government, insurance companies, and local households) could all achieve their targets. Local households are insured by insurance contracts against flood losses with a reasonable insurance premium. Vietnam Government might reduce its budget for subsidising local households after flooding by transferring flood risk to insurance companies. Insurance companies might make profits in long term as this market has a potential growth in Vietnam. One more important contribution of this paper is that this measure could guide land planning toward decisions which tend to minimize the total flood losses. 